\title{
Wildfire Occurrence: Integrated Model for Risk Analysis and Operative Suppression Aspects Management
}

\author{
Laura Bonora $^{1}$, Claudio Conese $^{1}$, Enrico Marchi ${ }^{2}$, Enrico Tesi $^{2}$, Niccolò Brachetti Montorselli $^{2}$ \\ ${ }^{1}$ Institute of Biometeorology (CNR-IBIMET), Sesto Fiorentino, Firenze, Italy; ${ }^{2}$ Department of Forest Science and Technology in \\ Forestry (DISTAF), Firenze, Italy. \\ Email: bonora@ibimet.cnr.it, c.conese@ibimet.cnr.it, enrico.tesi@unifi.it emarchi@unifi.it, montorselli@unifi.it
}

Received January $10^{\text {th }}, 2013$; revised February $15^{\text {th }}, 2013$; accepted February $20^{\text {th }}, 2013$

\begin{abstract}
Generally forest fires are related to human activities and need an effective fire prevention and suppression organization, based on a deep knowledge of the territory, fire behaviour and suppression system resources network. To organise monitoring, prevention and fire fighting operations, the knowledge of the risk level for different areas is important. To evaluate the probability that a forest fire occurs and to organise prevention and management of fire fighting activities, both simple and easy-to-use risk and operational difficulty indices were implemented. CNR-IBIMET and DISTAF Dept., on commitment of Tuscany Region, developed a multistep process for the evaluation of the risk, that can be used to assess land planning and to organise seasonal fire fighting resources. This model is called Final Risk Index (FRI); it is the result of the combination of the following two indices, which are initially developed separately. The concerned indices are the Global Risk Index (GRI), and Operational Difficulty Index in Fire Fighting (ODIF). The fire risk index processes different parameters to generate two hazards: static and dynamic, merged to obtain the Global Risk Index (GRI). It is very helpful to estimate the probability of forest fire occurrence, but it does not provide information on forest fire extinction difficulties. The operational difficulty index in fire fighting (ODIF) resumes all the factors affecting fire fighting activity by air and by ground and suggests the extinction efficiency of forest fires in a given area. Thus FRI improves aspects of the fire prevention planning, focused to the needs of a public operative structure. The objective was modelling the links between the main components in ignition and fire fighting actions to produce an easy to use tool to face the emergences, also foreseeing forest fires regime changes in the coming decades.
\end{abstract}

Keywords: Wild-Land Fire; Ignition Risk; Infrastructural Risk; Meteorological Risk

\section{Introduction}

Forest fires are a major concern in many countries in Europe, most notably in the South, in the Mediterranean Region, but also in Central and Northern Europe. Fires are also a major threat in the Northern African countries, or in the Eastern part of the Mediterranean.

Increased fire activity in many of these areas has been linked in the past to changes in land-use and land-cover due to the abandonment of the land and consequent socioeconomic changes.

Climate change, by elevating temperatures and reducing precipitation, will add further risk. Furthermore, increasing climate (droughts) or weather (heat waves) extremes are additional threats that we need to be prepared for in the coming years and decades.

In this framework, considering the necessity to safeguard forested areas with particular attention to Mediterranean ecosystems prone to wildfire, the present work has been performed on the whole Tuscany Region terri- tory to define a method to classify both ignition risk and operational constrains. An estimation of the risk for all the different forest ecosystem, considering natural and human components of landscape [1], is also very important; the aims is to establish effective and efficient activities for monitoring, prevention and restoration. It is opportune to consider that in Tuscany the highest number of forest fires (more than 90\%) depends on human activeties [2], in a direct or indirect way.

The ignition probability depends on a very large numbers of parameters, which should be considered and analysed simultaneously [3].

For the above reasons the Tuscany Region decided to develop a multistep model for the evaluation of the territorial risk and constrains; this model is named Final Risk Index (FRI) and is the final result of the combination of two indices, initially developed separately; these indices are the Global Risk Index (GRI) and the Operational Difficulty Index in Fire Fighting (ODIF).

The GRI gives landscape classification of the trigger- 
ing risk, analysing the territory (vegetation, morphology, infrastructures) and weather conditions.

The ODIF provides information related with the difficulties of suppression, taking into account infrastructural and morphological variables, fire fighting resources and facilities.

The FRI definition is based on ad-hoc experimental elaboration of historical meteorological data, because of measured data difficult collection. In the future operational phase the meteorological index will be derived by application of Canadian Fire Weather Index (Canadian Wildland Information System-Canadian Forest Service) using the meteorological data measured and collected by the Regional Hydrological Service. The results of the present work supply the necessary indications on the relevance of different meteorological parameters in ignition risk definition and the influence of these data on fuel risk level [4].

\section{Global Risk Index Input Data and System Structure}

To elaborate the Global Risk Index GRI following data have been used:

1) Historical meteorological data,

2) Urban road network and urban areas,

3) Tuscany forest inventory (IFT),

4) Historical statistic of forest fires (AIB),

5) Digital Terrain Model (DTM).

Concerning data collection it is important to specify that the described methodology has been defined and developed for Tuscany Region and similar Administrations using their institutional territorial information and data, regularly collected and updated [5].

1) Dataset of meteorological database of the National Meteorological Service (ASCII format); daily meteorological data stored from 1960 to 2003 with the following information:
- T, minimum and maximum

- Relative humidity

- Wind velocity

- Rainfall

- Sunshine duration, relative

The meteorological dataset is referred to a pixel of 30 $\mathrm{km}$; the data for each forested pixel (Forestry Inventory pixel of $400 \times 400 \mathrm{~m}$ see point 3 ) is defined by interpolation (Shepherd Method) of the 4 nearest meteorological stations.

2) The network of public roads and urban areas are derived from the Technical Regional Cartography (1: 10.000)

3) The Tuscany forest inventory (IFT) (last updating 1999), based on a pixel unit of $400 \mathrm{~m}$, represents the cartographic unit for the data processing in the present work. All the analysis performed on the IFT are referred to the pixels classified from class 3.1 to class 3.3.5 of CORINE, that group the different forest typology (total cells considered: 83.786).

4) Fire Ignition Point dataset (AIB dataset MSAccess format) gives coordinates of forest fire ignition points from 1984 to 2003.

5) The Digital Terrain Model (resolution $10 \mathrm{~m}$, grid format); slopes, aspect and elevation of regional territory. The structure and flow chart of the input data and work steps are in the Figure 1).

The GRI structure is the combination of the parts A) and $\mathrm{B}$ ) described in the 2.1 and 2.2 sections.

\subsection{A) Static Fire Hazard}

It refers to all factors not changing in time or changing very slowly. It is subdivided into two components:

- Intrinsic Factor, obtained considering components stable in time and space, as morphological features (slope and aspect), that give the morphological factor, and vegetation cover.

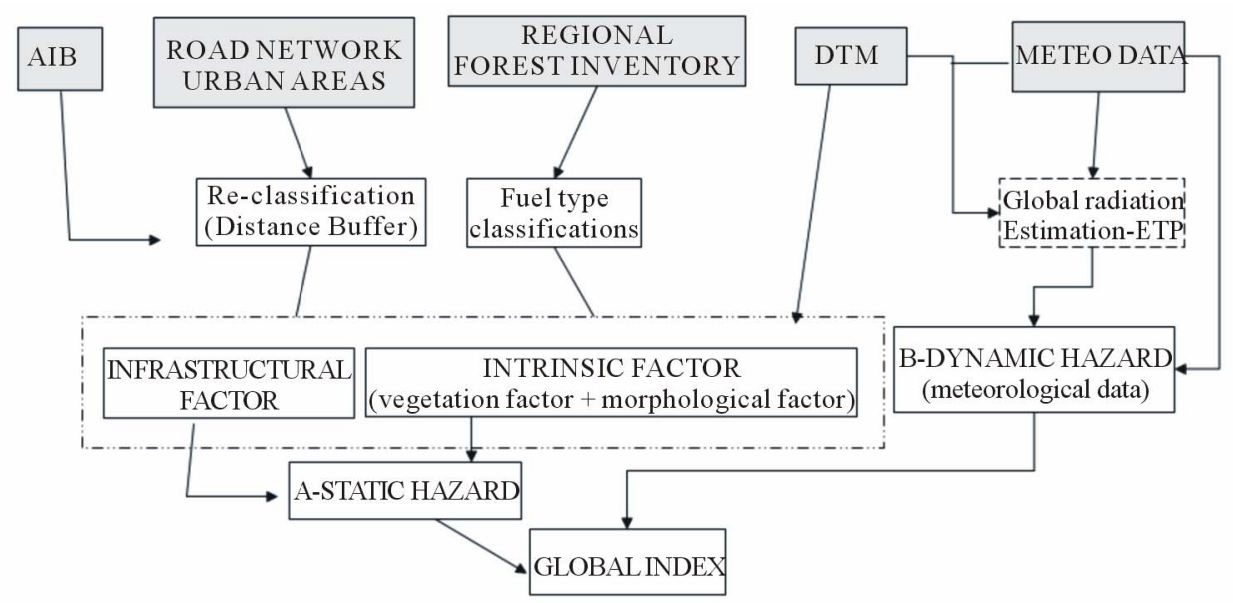

Figure 1. Global Risk Index (GRI) flowchart. 
- Infrastructural Factor, obtained considering any structure connected with the human activities. Urban areas and road networks have been considered in this case.

\subsubsection{Intrinsic Factor}

The model takes into account the slope and the aspect as Morphology Factor. The slope affects the fire propagation by rolling of heated materials and by contact of the canopy. The aspect affects the plants water contain stressing the fuel in south exposition.

On the basis of the test area features and according to the results of forest fires database analysis, the following classes of relative hazards have been defined and assumed as default classes (Figures $\mathbf{2}$ and $\mathbf{3}$ ).

The slope and aspect influence has been weighted differently on the morphological hazard introducing a further multiplicative factor, based on statistical analysis of historical fire events in Tuscany (AIB) and takes into consideration the irregular distribution of vegetation and landscape complex morphology. For slope the factor is 0.6 while for the aspect it is 0.4 .

The morphological hazard is calculated with following mathematical formula:

$$
\text { Morphological Hazard }=(\text { Slope*0.6) }+(\text { Aspect*0.4) }
$$

Intrinsic Factor considers also the influence of vegetation on the fire ignition; this component is weighted according to the physiologic vegetation status (presence/ absence of lives, quiescence/metabolic activity status etc.) in summer, in which the most number of events happen
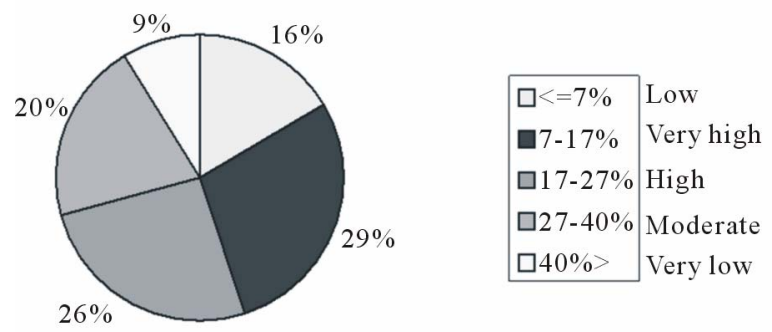

Figure 2. Risk level derived from distribution of fires events (A.I.B. database) in different slope classes.

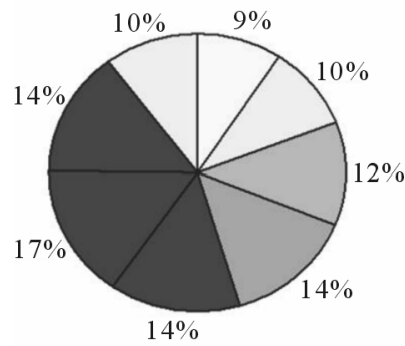

$$
\begin{array}{|l|l}
\hline \square \mathrm{N} & \text { Very low } \\
\square \mathrm{NE} & \text { Very low } \\
\square \mathrm{E} & \text { Low } \\
\square \mathrm{SE} & \text { Moderate } \\
\square \mathrm{S} & \text { Very high } \\
\square \mathrm{SW} & \text { Very high } \\
\square \mathrm{W} & \text { High } \\
\square \mathrm{NW} & \text { Very low } \\
\hline
\end{array}
$$

Figure 3. Risk level derived from distribution of fires events (A.I.B. database) in different aspect classes. in Tuscany. No micro-meteo aspects of vegetation (ex.: humidity contents, damp foliage, phenological phases etc.) have been considered, to have a tool requiring a less complex dataset.

To obtain the final Intrinsic Factors grid map, the morphology and vegetation influences are combined with the following formula:

$$
\begin{aligned}
\text { Intrinsic hazard } & =(\text { vegetation hazard } * 0.6) \\
& +(\text { morphological hazard } * 0.4)
\end{aligned}
$$

where the vegetation component have been weight more than the morphologic components according to the results of Tuscany Region annual statistics showing the dominant influence of vegetation in forest fire trigger.

\subsubsection{Infrastructural Factor}

It concerns road network density per square kilometre and distance from the urban areas. The relevance of these two components is related to the influence, statistically evaluated, of human activities in ignition events around roads and urban areas. For the road network, a different hazard level is assigned according to the road-line density per square kilometre. Five classes are defined on the basis of Natural Breaks Jenkins classification [6], from value "0" very low and value " 4 " very-high.

The urban areas are defined and classified according to the urban areas layer created by Tuscany Region. The hazard levels have been assigned on the basis of distance buffer from urban boundaries, using the same classification method applied for the road network.

In this case the multiplicative factors that have been considered to weigh the road and urban layers are respectively 0.6 and 0.4 , according the results of AIB statistical analysis, showing higher fire events frequency nearer roads than urban areas.

The final computation of Infrastructural Hazard Layer is obtained using following formula:

$$
\begin{aligned}
\text { Infrastructural Hazard } & =(\text { road factor } * 0.6) \\
& +(\text { urban factor } * 0.4)
\end{aligned}
$$

Finally the Static Hazard Risk component is computed in raster format as the sum of previous factor:

$$
\begin{aligned}
\text { Static Hazard } & =(\text { Intrinsic Hazard 0.6) } \\
& +(\text { Infrastructural Hazard } * 0.4)
\end{aligned}
$$

\subsection{B) Dynamic Fire Hazard}

The dynamic factor takes in account short-term varying parameters; in particular meteorological ones affecting fire ignition probability [7]:

- Temperature: high temperature influences the evapotranspiration rate and increases the litter drying speed and consequently the ignition probability. 
- Rainfall: rainfalls determine forest and agricultural ecosystem water balance.

- Day-since rain number: this factor have been introduced in the model to quickly classify the ecosystem water decreasing. Statistically very intense fires can occur from the $2^{\text {nd }}$ or $3^{\text {rd }}$ days after precipitation, because fuel requires significant humidity increasing to return to moisture extinction point. The day-since rain represents an estimation of the progressive water-loss of ecosystem, and this factor is weighted with the rainfall threshold.

- Rainfall threshold: is the mm of precipitation during a period. Different seasonal thresholds are defined to represent water quantity needed by an ecosystem to reach the moisture extinction point.

- Global radiation: influences the fuel drying speed.

Meteorological factor are combined to elaborate two different meteo-related hazards:

- Thermal Hazard Factor (TFH), computed by means of the maximum air temperature analysis and

- Drought Hazard Factor (DFH), which takes into account the net rain and the days-since rain number.

In particular, for Thermal Hazard Factor, wildfire distribution has been analysed in relation to the maximum temperature values and a threshold has been defined to classify temperature hazard.

A seasonal index has been produced by analysis of daily data. Each daily temperature value, assigned to one of five intervals requested by Tuscany Region commitment (improvement of E.U. requirements), is normalised on the basis of the intervals thresholds value.

Then the daily TFH index is summarised for each season to obtain the average value, between 0 and 4 .

The Drought Hazard Factor is daily computed and then integrated for each season. The drought index is identified in two phases: rain net definition, rainy days definition. The first step is to identify a threshold to discriminate the moisture condition of the ecosystem; this indication of "moisture extinction point" is computed using a double value (net and potential) of evapotranspiration in order to define a threshold representative of a complete moisture condition (Turc equation, the most suitable for estimate ETP when weather dataset are incomplete) [8,9]

For each day and the values, for each season, have been summarised using the equation:

$$
\text { Seasonal Threshold }=\sum_{s d}^{e d} e t p \times 2
$$

where $s d$ and $e d$ are the first and last day of the season.

Net rain is computed by following conditions on the daily rainfall value. The first step is the definition of the current day as a dry or a wet day:

- Wet day (rainy day) rain value greater than $0 \mathrm{~mm}$ and day before wet, or value greater than threshold on the day before dry.

- Dry day (rain $=0$ ) day without mm of rain.

- Rain value greater than 0 , but lower than the threshold, the rainfall is cumulated for each rainy day (rain event $=$ consecutive rainy day) until a dry day (rain $=$ 0 ) or until the cumulated rainfall exceeds the threshold.

The day-since rain number is calculated by an iterative counter. It expresses the number of no-rain days before the current day. The first day the counter is set with the number of day since the last net rain event. For each day without net rain the counter is increased by one. The counter is set to 0 when a wet day occurs.

If there are consecutive rainy days, the counter remains at zero until a no-rain day occurs. Then the count of the days starts again. At the end of the calculation, each day will have a number to which we have assigned a value in relation to a hazard level:

Day-since rain $=0->0$

Day-since rain $>0$ and day-since rain $<12->$ Value range between 1 and 3 according a linear function

Day-since rain $>=12->4$

The mean of the two indexes (TFH and DFH) gives the Dynamic Hazard Factor.

\subsection{Global Index (GRI)}

The static and dynamic hazard are mathematically combined in the model to obtain the global fire hazard model (gfh).

$$
\begin{aligned}
\text { global index } & =(\text { static hazard } * 0.6) \\
& +(\text { dynamic hazard } * 0.4)
\end{aligned}
$$

the lower weight of dynamic hazard is due to the fact that available meteorological data base was not completely reliable for this application because the historical data were not up-dated regularly in time and space, the actual ones are collected prevalently in plain agricultural ecosystems.

\section{Operative Difficulty Index in Fire-Fighting}

The ODIF Index takes in consideration several factors affecting the extinction activities carried out by the air-based resources and fire crews [10,11]. The result is an estimation of the efficiency and effectiveness of the fire fighting organization in an area. The values taken in consideration in the present work are the results of statistical evaluation to extrapolate the min and max value for each variable.

The factors concerning ODIF are:

Vehicles Access Time (VAT): travel time needed to a fire engine for moving from its base to the road nearest to 
burning area.

Helicopter Access Time (HAT): flight time needed to fly from the helibase to the fire.

Fire-fighters Operative Difficulty (FOD): the fire hose can lay down on a flat terrain or downhill completely (negative slope), while uphill (positive slope). The manageable length depends on the capacity of the personnel to carry the hose. So the optimum theoretical values are between 25 and $100 \mathrm{~m}$ upslope with a maximum gradient of $60 \%$ and between 50 and $400 \mathrm{~m}$ down slope or on a flat terrain.

Vehicles Supplying Time (VST): time needed to a fire engine to reach the nearest supplying water point from the fire.

Helicopter Supplying Time (HST): time needed to an helicopter to reach the nearest supplying water point from the fire.

To process the ODIF factors a linear fuzzy function was applied giving values ranging from 0 to 1 , according to the "fuzzy logic" that it has been already applied in other environmental analysis $[12,13]$. This logic bring to the definition of a "fuzzy set" in which "the values given to each element drop inside a continuous interval $(0,1)$, that creates an index which expresses the belonging grade of each element to the define set: values close to 1 mean an high grade of belonging to the set, while values close to 0 indicate a low grade of affinity of the element to the definition that characterizes the set.

The function is applied to every pixel of the territory analyzed and to every factors included in the model, using the formula below

$$
\text { idFactors }=\frac{\text { Value }- \text { min }}{\max -\min }
$$

The mathematical elaboration of these data gives some intermediate indices:

Ground Operational Difficulty Index (GODI) calculated as:

$$
\text { GODI }=\max (\text { idVAT, idVST, idFOD })
$$

Helicopters Operational Difficulty Index (HODI) calculated as:

$$
\text { HODI }=\text { max }(\text { idHAT, idVST })
$$

Finally GODI and HODI are combined to obtain the ODIF:

$$
\mathrm{ODIF}=(\mathrm{GODI} * 0.7)+(\mathrm{HODI} * 0.3)
$$

The multiplicative factors introduced to weight the variables are determined on the basis of the experience of Tuscany fire managers (AIB), the analysis of forest fire and helitanker database showing that $70 \%$ of the effort for fire extinguishing is sustained by fire crew and 30\% by aerial fire fighting [14].

\section{Final Risk Index FRI}

The combination of the GRI and ODIF represents the necessity to foreseen both prevention and well structured fire fighting operative planning, taking in mind the increasing risk of fire ignition and spread.

In this framework the five classes listed below express the growing complexity in territory management in terms of pre and during fire events.

The difficulty is affected by the surface classified in each different class; the larger it is, the more complex the integrated management of two aspects is. For the first three classes, giving the general low level of risk, the surface extension is not so relevant, on the contrary of the last two.

GRI and ODIF have been joined by analysing all possible combinations (pixel by pixel) of the two variables and the results have been classified as following:

Class 0: Very low total risk. No fire planning or prevention activity is needed.

Class 1: Low total risk. The standard operational procedures and prevention activities are needed.

Class 2: Moderate total risk. Some specific procedures and prevention activities may be organized, like patrolling activity during the most dangerous times of day.

Class 3: High total risk. If a few areas are in this class, only some specific prevention procedures and infrastructure maintenance may be applied. If large areas are in this class, a medium-long term infrastructure planning has to be applied (forest road planning and maintenance, water point construction and maintenance, helitanker bases or fire-fighter centres reallocation analysis).

Class 4: Very high total risk. If a few areas are in this class, only some specific prevention procedures and infrastructure maintenance may be applied. If large areas are in this class, both specific prevention procedures and short term infrastructure planning have to be applied.

\section{Conclusions}

The GRI and ODIF indices are expression of different concepts from the point of view territory planning and management because the first one gives a risk level of

Table 1. Combination matrix of GRI and ODIF.

\begin{tabular}{ccccccc}
\hline & \multicolumn{7}{c}{ ODIF value } \\
\hline \multirow{2}{*}{ GRI value } & 0 & 1 & 2 & 3 & 4 \\
& 1 & 0 & 0 & 1 & 1 & 1 \\
& 2 & 0 & 1 & 2 & 2 & 3 \\
& 3 & 1 & 2 & 2 & 3 & 4 \\
& 4 & 1 & 2 & 3 & 4 & 4 \\
\hline
\end{tabular}


fire starting, conversely the second one express not a risk but the difficult to optimize operational chain and structures distribution.

Considering that, it is no possible to merge directly them because the trade union parameter is just the fire incidence on territory; so the guideline has been the experience and suggestions of stakeholders to derive indications useful both for planning department and civil protection operative structures.

At Regional level, the results reflect the level of warning recorded by the Regional fire fighting organization. In fact, most of the Region has a "very high" or "high" global risk in summer. For the summer season, this risk distribution is strictly related to the meteorological conditions, e.g. high temperature and low precipitation. Even in winter, with low temperature and presence of rainfall, the percentage of areas classified "very high" by the system is, however, $15 \%$. This value is mainly due to some areas of the Apennines mountains in which the meteorological conditions and aspect increase the risk level during the winter.

To plan forest fire fighting, on the basis of the analysis carried out a careful planning of infrastructure and prevention activity on about $30 \%$ of the territory is suggested.

This operational index can be applied to large areas with diverse characteristics considering the relative low number and easy availability of input data that can be managed also by territorial bureaus and public structures devoted to forest fire planning.

\section{REFERENCES}

[1] X. Viegas, G. Bovio, A. Ferreira, A. Nosenzo and B. Sol, "Comparative Study of Various Methods of Fire Danger Evaluation in Southern Europe,” International Journal of Wildland Fire, Vol. 9, No. 4, 2000, pp. 235-246. doi:10.1071/WF00015

[2] Tuscany Region, "Piano Operative Antincendi Boschivi," Produzioni Editoriali Regione Toscana, November 2004.

[3] E. Chuvieco, F. J. Salas, L. Carvacho and F. Rodriguez-Silva, "Integrated Fire Risk Mapping," In: E. Chuvieco, Ed., Remote Sensing of Large Wildfires, Springerverlag, New York, 1999, pp. 66-100. doi:10.1007/978-3-642-60164-4_5
[4] C. Conese, L. Bonora, M. Romani and E. Checcacci, "Forest Fire Hazard Model Definition for Local Land User (Tuscany Region),” Atti del IV Congrès International Environnement et Identité en Mediterranée, Corte, 19-25 Juillet 2004.

[5] J. San-Miguel-Ayanz, P. M. Barbosa, G. Schmuck and G. Libertà, "The European Forest Fire Information System (EFFIS)," Joint International Workshop of EARSeL SIG on Forest Fires and the GOFC/GOLD-Fire Program: Innovative Concepts and Methods in Fire Danger Estimation, Ghent, 5-7 June 2003.

[6] G. F. Jenks and F. C. Caspall, "Error on Choropletic Maps: Definition, Measurement, Reduction,” Annals of the Association of American Geographers, Vol. 61, No. 2, 1971, pp. 217-244. doi:10.1111/j.1467-8306.1971.tb00779.x

[7] J., San-Miguel-Ayanz, "Methodologies for the Evaluation of Forest Fire Risk: From Long-Term (Static) to Dynamic Indices,” In: T. Anfodillo and V. Carraro, Eds., Forest Fires: Ecology and Control, Univesity degli Studi di Padova, 2002, pp. 117-132.

[8] S. Trajkovic and S. Kolakovic, "Evaluation of Reference Evapotranspiration Equations under Humid Conditions Water Resources Management” Springer, New York, 24 February 2009.

[9] R. E. Yoder, O. Odhiambo and W. C. Wright, "Evaluation of Methods for Estimating Daily Reference Crop Evapotranspiration at a Site in the Humid Southeast United States," Applied Engineering in Agriculture, Vol. 21, No. 2, 2005, pp. 197-202.

[10] G. Bovio, “Comportamento Degli Incendi Boschivi Estinguibili con Attacco Diretto,” Monti e Boschi, Vol. 44, No. 4, 1993, pp. 19-24.

[11] G. Hippoliti, "Note Pratiche per la Realizzazione Della Viabilità Forestale,” Compagnia delle Foreste, Arezzo, 2003.

[12] L. W. Carter and L. G. Hill, "Handbook of Variables for Environmental Impact Assessment,” Ann Arbor Science Publisher, 1981.

[13] L. Borselli, "Vantaggi Delle Tecniche Matematiche Fuzzy Nelle Scienze Ambientali Della Terra e del Suolo," CNRISE, Firenze, 2002.

[14] E. Marchi, E. Tesi, N. B. Montorselli and F. Neri, "Helicopter Activity in Forest Fire-Fighting: A Data Analysis Proposal," Proceedings of the 5th International Conference on Forest Fire Research, Figuera da Foz Portugal, 27-30 November 2006. 